\title{
DA MÃO DE FERRO AO ROMANTISMO: A PRODUÇÃO DO GÊNERO NO DISCURSO DA
} LITERATURA POP MANAGEMENT.

Izel Aparecida Molinete

Bacharel em Ciências da Administração

Universidade Federal de Santa Catarina

Florianópolis - Santa Catarina - Brasil izelmolinete@gmail.com

Rebeca de Moraes Ribeiro de Barcellos Doutora em Administração

Universidade Federal de Santa Catarina

Florianópolis - Santa Catarina - Brasil rebecamribeiro@gmail.com

Helena Kuerten de Salles

Doutora em Administração

Universidade Federal de Santa Catarina

Florianópolis - Santa Catarina - Brasil

helenasalles@yahoo.com.br

\section{RESUMO}

Em um contexto de divisão sexual do trabalho e de naturalização da atribuição de determinadas tarefas às mulheres e outras aos homens, a diferenciação entre os gêneros é produzida e reproduzida pelo que Lauretis (1994) chamou de tecnologias de gênero. No campo dos Estudos Organizacionais, entendemos que os livros e revistas de consumo rápido produzidos pela mídia de negócios, a chamada literatura pop management, é uma destas tecnologias. Considerando a Análise Crítica do Discurso uma abordagem que pode contribuir para a discussão sobre discursos sexistas, relações de poder e/ou exclusão social o objetivo deste trabalho foi evidenciar e compreender como são representados e, portanto, produzidos e reproduzidos, os gêneros masculino e feminino em posições de gestão por reportagens de capa da Revista Voce SA. publicadas nos últimos cinco anos. Nossa análise, destaca que os textos reforçam os estereótipos dominantes de gênero. Com base no conceito de tecnologia de gênero, observamos que as reportagens da revista constroem gênero ao retratar o gestor e a gestora com atributos masculino e feminino, respectivamente, definindo-os e diferenciando-os como mulher e homem. São as marcas sociais, definidas pelos atributos construídos no discurso da revista, que posicionam estas pessoas como gestora mulher e gestor homem. As representações estereotipadas destas pessoas detêm a força de se estabelecer como limitadores sobre as escolhas e possibilidades de ação social dos indivíduos ao conferir uma aparência de normatividade à gestão sob a perspectiva do gênero, uma vez que os discursos construídos por esta literatura contribuem para a disseminação de ideias e práticas gerenciais entre os praticantes e nas organizações.

Palavras-chave: Análise crítica do discurso; Atributos de gênero; Gênero; Gestão.

\section{FROM THE IRON HAND TO ROMANTICISM: THE PRODUCTION OF GENDER IN THE DISCOURSE OF POP MANAGEMENT LITERATURE.}

\section{ABSTRACT}

In a context of sexual division of labor and naturalization of the division of certain tasks between women and men, gender differentiation is produced and reproduced by what Lauretis (1994) called gender technologies. In the field of Organizational Studies, we understand that fast-consuming books and magazines produced by business media, the so-called pop management literature, is one such technology. Considering the Critical Discourse Analysis an approach that can contribute to the discussion about sexist discourses, power relations and / or social exclusion, the objective of this work was to highlight and identify how the masculine and feminine genders are represented and thus produced and reproduced in management positions for cover stories of the magazine VOCÊ S/A, published in the last five years. Our analysis points out that the texts reinforce the dominant gender stereotypes. Based on the concept of gender technology, we observe that the articles construct gender by portraying the manager and the manager with masculine and feminine attributes, respectively, defining them and differentiating them as woman and man. They are the social marks defined by the attributes constructed in the discourse of the magazine that position these people as woman manager and man manager. The stereotyped representations of these people have the power to establish themselves as limiters on the choices and possibilities of social action of the individuals by giving a normative appearance to the management from the perspective of the genre, since the discourses constructed by this literature contribute to the dissemination of management ideas and practices among practitioners and organizations.

Keywords: Gender; Gender attributes; Management; Critical discourse analysis. 


\section{INTRODUÇÃO}

Embora condições sociais e históricas tenham influenciado na mudança das dinâmicas sociais relacionadas ao trabalho feminino, foi somente a partir da década de 1970 que a participação da mulher no mercado de trabalho tornou-se notória no Brasil. Essa inserção das mulheres no mundo do trabalho e, especificamente, no contexto organizacional, gerou impactos tanto no comportamento da mão-de-obra como também na organização do trabalho (Cappelle et al., 2013). Ainda assim, as organizações são ambientes fortemente marcados por valores masculinos (Acker, 1990), nos quais as noções dominantes de racionalidade sustentadas e valorizadas são articuladas a uma concepção tradicional de masculinidade que afeta diretamente as expectativas sobre todos os indivíduos (Eccel, 2010).

Estas expectativas atuam em um contexto de divisão sexual do trabalho (Kergoat, 2009) e de naturalização da atribuição de determinadas tarefas às mulheres e outras aos homens e na determinação dos papéis sexuais (Miguel, 2001). Desta forma, a interface entre gênero e trabalho mostra-se um panorama privilegiado para análise das relações de poder, de desigualdades e de consequências da dicotomia entre masculino e feminino (Eccel, 2010).

Conforme Cranny-Francis et al (2003), as identidades de gênero são socialmente construídas, o que quer dizer que a definição de gênero não é definida pelo aspecto biológico masculino e feminino, mas sim pelos comportamentos idealizados pela sociedade Neste contexto, o conceito de gênero deve ser entendido de forma ampla, caracterizando-se não como diferenciação de caráter biológico, mas como um leque abrangente de aspectos que vão desde as manifestações culturais até os seus reflexos nas representações construídas pela sociedade (Vilas Boas; Neto; Cramer, 2003; Louro, 2014). O gênero se torna, portanto, uma maneira de indicar a criação inteiramente social sobre os papéis próprios aos homens e às mulheres, constituindo como uma categoria social imposta sobre um corpo sexuado (Scott, 1995).

As experiências generificadas e a construção da identidade são produzidas e reproduzidas pelo discurso, aqui entendido com um elemento de qualquer prática social (Fairclough, 2003). Como representação e como autorrepresentação, o gênero é produto de diferentes tecnologias sociais, tais como o cinema e outras formas de mídia, por exemplo, e de discursos e práticas da vida cotidiana (Lauretis, 1994). Por meio destas práticas se delimitam atividades categorizadas como femininas e masculinas, estabelecendo a internalização e a reprodução das relações entre homens e mulheres, inclusive aquelas caracterizadas por estereótipos, "[...]crenças partilhadas sobre determinadas qualidades que se reconhecem como características de indivíduos, em função da sua inclusão num dos grupos de gênero, portanto, feminino ou masculino" (Miranda, 2008, p.6).

A categorização do eu e do outro é reproduzida e reforçada pela atribuição de traços culturalmente construídos como próprios de cada gênero. Ao masculino tendem a ser associados alguns atributos, tais como ambição, afirmação, força, liderança, agressividade, propensão a riscos, e ao feminino, a compreensão, passividade, sensibilidade, simpatia, alegria (Diniz, 2016). Argumentamos que essa relação de determinados atributos a gêneros específicos é construída e perpetuada socialmente pelo discurso (Fairclough, 2001), sendo que na perspectiva dominante as mulheres são menos aptas do que os homens para trabalhos que priorizem autoridade, habilidades técnicas, força, mas como adequadas para aqueles que requerem as habilidades sociais, por exemplo (Kergoat, 2009). Neste contexto, a relação entre atributos de gênero e trabalho, incluídos numa discussão mais ampla, acaba por categorizar as profissões como masculinas e femininas.

Tal processo classificatório, operado com base em determinados atributos de gênero, é produzido e reproduzido pelo que Lauretis (1994) chamou de tecnologias de gênero. No campo dos Estudos Organizacionais, entendemos que a literatura pop management (Wood Jr; Paula, 2002) é uma destas tecnologias. Tendo surgido nos anos de 1980 nos Estados Unidos e adaptada ao contexto brasileiro no final da década de 1990, esta linha editorial passou a influenciar na disseminação de modismos gerenciais, dado o seu amplo alcance e apelo popular. No cenário nacional, a revista Você S/A, lançada em 1998, se destaca por tratar de temas como carreira, 
finanças pessoais e qualidade de vida. A circulação impressa da revista é de 51.000 exemplares, lidos por estimados 263.000 leitores. Nas redes sociais, a revista tem 253 mil seguidores no Facebook e 589 mil no Twitter (Voce Sa, 2016).

A análise das questões de gênero neste tipo de literatura ainda é assunto pouco explorado no Brasil. O estudo de Diniz (2016), por exemplo, conclui que as práticas discursivas da revista Exame podem ser vistas como alargadoras e como constituidoras da estrutura patriarcal, reforçando a feminilidade tradicional, ainda que com novos contornos.

Sobre a mesma revista, Medeiros, Borges e Miranda (2010) realizaram uma análise semiótica das capas com o objetivo de identificar a contribuição desta mídia para a reificação de modelos estereotipados de homens e mulheres no mundo dos negócios. Este estudo demonstra que as capas são definidas de forma a significar que a carreira executiva pertence ao universo masculino reforçando, ao mesmo tempo, que para as mulheres existe a expectativa distante de que esse quadro se modifique (Medeiros; Borges; Miranda, 2010). Também por meio de análise semiótica das capas, mas incluindo além da Revista Exame a Revista Voce Sa, Melo et al (2004) destacam a multiplicidade de representações da mulher, incluindo visões tradicionais e contemporâneas do que seja feminino, como esposa/namorada, supermulher, esportista, executiva, sensual, consumidora, econômica, mulher produto e mulher solidária.

Percebe-se que há uma lacuna na análise destas publicações, do ponto de vista do gênero, qual seja desnudar os discursos de publicações pop management acerca de homens e mulheres de forma comparativa, colocando em perspectiva relacional, essência do conceito de gênero, a forma de se representar homens e mulheres em posições executivas.

Lauretis (1994) afirma que as posições diferenciadas colocadas à disposição de homens e mulheres no discurso são algumas das formas de explicar o conteúdo das diferenças de gênero. Neste contexto, a linguagem, como parte do discurso, produz e reproduz a realidade em que estamos inseridos e, desta forma, a construção de gênero pode ser identificada ao se analisar as características léxico-gramaticais de um determinado texto (Heberle, 2000).

Enfatizamos que o papel das instituições na atribuição de posições sociais aos indivíduos é relevante no que diz respeito à determinação de categorias socioculturais em nossa sociedade, tais como idade, classe, gênero e etnia. A autoridade institucional, seja como uma forma organizacional ou como a solidificação de um comportamento social, é capaz de constituir, transmitir e moldar as ordens de gênero (Eckert \& Mcconnell-Ginet, 2003). Segundo van Dijk (2010, p.357) “[...]os receptores tendem a aceitar crenças, conhecimento e opiniões através do discurso proferido por fontes percebidas como autorizadas, confiáveis ou críveis, tais como acadêmicos, peritos, profissionais ou pela mídia confiável". Neste sentido, o discurso das organizações participa da definição e legitimação de determinadas estruturas sociais e por isso pesquisas dessa natureza são relevantes para os debates de gênero em estudos organizacionais.

Se o discurso da mídia é considerado legítimo e tem impactos concretos sobre a vida cotidiana das pessoas e "[...] as pessoas se constituem como resultado do fato de certas verdades e não outras estarem em voga" (Hollway apud Lauretis, 1994, p.225), a contribuição central do nosso trabalho reside na demonstração de como os gêneros feminino e masculino são produzidos pela literatura pop management, alertando sobre o viés ideológico desta construção a qual possui desdobramentos sobre as organizações e os praticantes, uma vez que a experiência do gênero remonta aos "[...] efeitos de significado e as auto representações produzidas no sujeito pelas práticas, discursos e instituições socioculturais dedicados à produção de homens e mulheres" (Lauretis, 1994, p.229).

Assim, compreendendo a literatura pop management como uma tecnologia de gênero e a ACD como abordagem que pode contribuir para a discussão sobre discursos sexistas, relações de poder e/ou exclusão social (Heberle, 2000), tivemos por objetivo analisar como são representados e, portanto, produzidos e reproduzidos, os gêneros masculino e feminino em posições de gestão pela Revista Você SA, considerando apresentação de perfis de executivos do sexo masculino e feminino, em reportagens de capa, nas edições publicadas nos últimos cinco anos. Para o desenvolvimento 
deste trabalho, apresentamos nas seções seguintes uma discussão teórica sobre gênero e atributos de gênero; sobre a literatura pop management e sobre a Análise Crítica do Discurso (ACD). Em seguida, apresentamos a análise do corpus selecionado para a pesquisa, bem como nossas reflexões sobre as particularidades evidenciadas nos textos analisados.

\section{GÊNERO E ATRIBUTOS DE GÊNERO}

O conceito de gênero foi engendrado e problematizado no âmbito das construções teóricas do feminismo de segunda onda, em meados dos anos 1960. Por intermédio das feministas anglosaxãs o termo gender passa a ser utilizado como distinto de sex, com o intuito de rejeitar o determinismo biológico da categoria sexo, acentuando o caráter social das distinções baseadas no sexo (Louro, 2014). Como argumenta a autora, não se pretende negar que o gênero se constitui sobre corpos sexuados, mas sim enfatizar deliberadamente a construção social e histórica produzida sobre características biológicas. No Brasil, no final dos anos 1980, as feministas passaram a utilizar o termo gênero, o qual recoloca o debate no campo do social, "[...] pois é nele que se constroem e se reproduzem as relações (desiguais) entre os sujeitos (Louro, 2014, p.26)

Além disso, a substituição do termo "mulheres" pelo termo "gênero" sugere que a informação sobre estas, engloba, necessariamente, as informações sobre os homens, abordando a questão sob uma perspectiva de relação social entre os sexos (Gondim et al., 2013; Louro, 2014; Vilas Boas; Neto; Cramer, 2003; Scott, 1995). Assim, gênero é uma categoria classificatória que remete ao papel que a construção cultural desempenha na definição social das diferenças sexuais. Esse conceito pretende questionar as formas culturais e simbólicas da criação social das relações sociais entre os sexos, assim como de todas as formas de classificação do que é entendido como masculino e feminino e dos seus efeitos sobre as diversas dimensões sociais e culturais (Machado, 2000).

Neste sentido, a distinção entre sexo e gênero se tornou primordial para o feminismo, partindo da ligação entre o primeiro ao fenômeno biológico e o segundo à construção social e codificando a expressão de feminilidade como naturalizada, cuja expressão é resultado de pressões, constrangimentos e expectativas sociais. Desta forma, gênero não é uma identidade, mas uma posição social e atributo das estruturas sociais (Miguel; Biroli, 2014). O gênero, portanto, organiza as vivências e as experiências pessoais e não se restringe às mulheres, suas relações perpassam toda a sociedade de maneira que as desigualdades inerentes às questões de gênero definem as posições tanto de homens quanto de mulheres na sociedade.

Neste contexto, as particularidades atribuídas ao feminino e ao masculino constituem elementos importantes na formação da identidade social dos indivíduos. Sendo o discurso parte importante da construção do gênero, há que se considerar a relação dos atributos na sua construção, produção e reprodução, visto que a sua diferenciação por meio de traços considerados próprios a um ou a outro permeia as diversas formas de segregação entre o masculino e o feminino. Conforme afirma Miranda (2008, p.6), é por meio da agregação de atributos específicos como forma de criar a essência de um grupo de pessoas que se constroem os estereótipos de gênero.

Assim, as noções tradicionais de masculinidade e feminilidade se caracterizam por "[...]um conjunto de simbolismos e estereótipos construídos social e historicamente a partir da cultura patriarcal" (Diniz, 2016, p.141). Neste contexto, a masculinidade está relacionada a alguns aspectos, tais como a assertividade e a tendência à individualidade, enquanto a feminilidade está associada ao cuidado e à preocupação com a coletividade (Gondim et al, 2013). Diniz (2016) reforça que a incorporação dos atributos relacionados às masculinidades e feminilidades tradicionais assume um caráter estratégico em uma cultura rigidamente regulada. Desta forma, os sujeitos se apropriam das dimensões atribuídas ao masculino ou ao feminino como forma de sobrevivência social e psíquica, inteligibilidade em contextos específicos e afirmação identitária positiva (Diniz, 2016).

O sistema de sexo-gênero é tanto uma construção social quanto um aparato semiótico, um sistema de representação que atribui significado a indivíduos na sociedade (Lauretis, 1994). Desta 
forma, quando um indivíduo é representado como masculino ou feminino, subentende-se desta representação a totalidade dos atributos sociais vinculados a este ou aquele gênero. Por isso Lauretis (1994, p.212) afirma que "[...]a representação de gênero é a sua construção[...]”, ou seja, “[...]a construção do gênero é tanto o produto quanto o processo de sua representação". Portanto, discutimos no tópico seguinte a literatura pop management como tecnologia de gênero com base em evidências textuais decorrentes do emprego da Análise Crítica do Discurso.

\section{TECNOLOGIA DE GÊNERO, LITERATURA POP-MANAGEMENT E ANÁLISE CRÍTICA DO DISCURSO}

Lauretis (1994) discute gênero como o efeito de uma variedade de representações e práticas discursivas, as quais produzem diferenças sexuais. Para a autora, gênero é uma configuração variável de posicionalidades sexuais-discursivas com a função de constituir indivíduos concretos em homens e mulheres.

Neste contexto, Lauretis discute o gênero como um conjunto de efeitos produzidos nos corpos, comportamentos e relações sociais por tecnologias sociais, tais como a mídia, as diversas epistemologias, práticas críticas institucionalizadas e práticas da vida cotidiana (Pereira, 2009). A estas tecnologias sociais que constroem o gênero, como produto e processo de representação e autorrepresentação, com implicações concretas na vida material das pessoas, Lauretis (1994) chamou de tecnologias de gênero.

A tecnologia de gênero não produz gênero apenas por meio do que ela representa, mas também daquilo que não é dito ou é silenciado. Como afirma Lauretis (1994, p.238), o gênero como representação ideológica pende entre "[...]a representação do gênero (dentro do seu referencial androcêntrico) e o que essa representação exclui, ou mais exatamente, torna irrepresentável".

Como esclarece Van Dijk (2010), os elementos de poder e de dominação surgem de várias maneiras, sendo a "mídia confiável" uma das fontes. Assim, sendo a literatura pop management composta por livros e revistas produzidos pela mídia de negócios, com alcance e público cada vez maior no Brasil, entendemos que seus discursos, ao representar indivíduos com atributos femininos ou masculinos, produzem gênero. Para sustentar esta afirmação, recorremos à ACD como concepção teórica e metodológica que considera o uso da linguagem como uma forma de prática social. O discurso consiste, então, em uma forma de ação por meio da qual as pessoas podem agir sobre o mundo e sobre os outros, assim como também é uma forma de representação da realidade (Resende; Ramalho, 2006).

Impulsionada pelo contexto de acirrada competição empresarial, a literatura direcionada às questões profissionais na área de Gestão e Administração, a chamada literatura pop-management, ganhou cada vez mais espaço no mundo dos negócios no Brasil a partir da década de 1980. Suas publicações abordam alguns temas, tais como as novas tecnologias gerenciais, dicas para o sucesso profissional e cases de sucesso empresarial (Wood Jr; Paula, 2002).

Enquanto meio de disseminação dos pressupostos do management, este conjunto de recursos midiáticos utiliza-se de algumas técnicas, tais como discurso unificado; linguagem simplificada; padronização de conceitos, modelos e métodos; construções simbólicas para problemas complexos dando a impressão de facilidade à compreensão destas questões; dicas e conselhos de como se chegar ao padrão de sucesso que é valorizado na cultura do management; exaltação às novidades em ferramentas de gestão, dentre outros (Carvalho; Carvalho; Bezerra, 2010).

Dada a importância que o discurso ocupa nas práticas sociais e, no contexto deste trabalho, considerando a mídia como tecnologia de gênero, recorremos à ACD a fim de elucidar as naturalizações ideológicas advindas de práticas discursivas, tornando claras as estratégias de preservação de poderes de grupos dominantes. Constitui-se, portanto, em campo interessado em investigar criticamente como assimetrias de poder são constituídas, legitimadas e expressas por meio do discurso, evidenciando seus efeitos e permitindo, a partir desta identificação, intervir na 
sociedade a fim de gerar mudanças, num caráter crítico e emancipatório (Wodak, 2004; Fairclough, 2001; Meurer, 2005).

A abordagem da ACD parte do pressuposto de que a linguagem é um elemento inerente a todas as práticas sociais sendo, por isso, uma alternativa viável para discussão de fenômenos sociais. De acordo com Fairclough (2003), parte-se do princípio que, por meio da linguagem, agimos, expressamos nossa visão de mundo e nos posicionamos enquanto indivíduos. Essas múltiplas funções exercidas pela linguagem são derivadas da teoria Linguística Sistêmico-Funcional de Michael Halliday (1994), a qual representa a base linguística da ACD. Com base nesta perspectiva, Fairclough (2003) assume que todo texto possui três significados, sendo eles: o acional, o representacional e o identificacional conforme demonstrado na figura 1.

\begin{tabular}{|l|l|}
\hline \multicolumn{2}{|c|}{ Significados da linguagem } \\
\hline Acional & $\begin{array}{l}\text { O significado acional focaliza o texto como modo de (inter) ação em } \\
\text { eventos sociais, legitimando ou questionando as relações } \\
\text { sociais. }\end{array}$ \\
\hline Representacional & $\begin{array}{l}\text { O significado representacional enfatiza a representação de aspectos do } \\
\text { mundo em textos. }\end{array}$ \\
\hline Identificacional & $\begin{array}{l}\text { O significado identificacional refere-se à construção e à negociação de } \\
\text { identidades no texto. }\end{array}$ \\
\hline
\end{tabular}

Figura 1: Significados da linguagem

Fonte: Fairclough (2003).

Segundo Salles, Heberle e Macedo (2013), apesar da necessidade de analisar o evento discursivo nas dimensões textual, discursiva e sociocultural, o mesmo não se aplica aos significados realizados pela linguagem, podendo-se, para fins de análise, abordar o discurso a partir de um dos significados de interesse específico. Neste estudo, nosso interesse foi demonstrar, de forma comparativa, como a literatura pop management, especificamente as reportagens veiculadas na Revista Você S.A., atribuem características de gênero a perfis de profissionais de gestão. A ACD foi realizada com foco no significado representacional, evidenciando como um gestor e uma gestora são representados, de forma que pudéssemos verificar a associação de atributos específicos do gênero masculino e do gênero feminino aos perfis profissionais, demonstrando, por meio do discurso, a forma como a revista constrói e fixa o gênero em um escopo ideológico androcêntrico, tornando invisíveis dinâmicas não hegemônicas de atuação de homens e mulheres construídas cotidianamente nos interstícios das instituições e nas contrapráticas (Lauretis, 1994).

\section{A REVISTA VOCÊ S/A E OS PROCEDIMENTOS DE ANÁLISE}

A Revista Você S/A teve seu lançamento no ano de 1998 e surgiu como uma extensão da Revista Exame a partir da percepção no aumento das vendas de exemplares quando os temas de capa tratavam de carreira e trajetória profissional. Assim, a partir deste lançamento, houve uma segmentação do público-alvo entre a Você S/A e a Exame: a primeira, voltou-se para a pessoa física e a segunda, para a jurídica. Focada no indivíduo enquanto profissional, a revista Você S/A investiu numa literatura facilitada, pautada pelo tom informal e coloquial, fazendo com que seus leitores a utilizassem como um instrumento de autoajuda e até mesmo como um referencial de comportamento (Wood Jr; Paula, 2002).

Sob a justificativa de que o mercado de trabalho está cada vez mais dinâmico e imprevisível, as pessoas, preocupadas em como manter sua empregabilidade, passaram a procurar cada vez mais por conteúdos relacionados a esta temática. Desta forma, a revista atenta a este novo nicho, surgiu com a proposta de fornecer conteúdos especializados na área de gestão e carreira (Melo et al. 2004). 
De acordo com informações da revista, esta é lida por mais de 260 mil pessoas todos os meses, em suas versões impressa (51 mil exemplares) ou digital. Sobre o público de leitores da revista, a maioria tem entre 30 e 39 anos de idade e pertence às classes $\mathrm{A}$ e B, sendo que $57 \%$ são mulheres. Entre os leitores e leitoras, 64\% concordam que a revista tem força e influência sobre a opinião das pessoas (Voce Sa, 2016). Conforme estudo realizado por Medeiros, Borges e Miranda (2010, p. 87) o público-alvo da revista caracteriza-se por pessoas que ocupam cargos envolvendo a tomada de decisão em diferentes âmbitos organizacionais.

O corpus desta pesquisa foi constituído de forma a dar visibilidade à forma como o gestor homem e a gestora mulher são retratados nas reportagens analisadas, avaliando a relação entre os atributos descritos e o gênero dos indivíduos. Neste sentido, a ACD nos forneceu o suporte necessário para refletir sobre um processo de ideologização acerca do gênero, reforçando estereótipos. Para composição do corpus, foram levantadas, por meio do acervo online da revista, disponível em seu website, as edições publicadas no recorte temporal dos últimos cinco anos, compreendidos entre os anos 2011 a 2015, totalizando 54 edições. Deste total, em março de 2016 foram selecionadas aquelas cujas reportagens de capa tivessem como objeto a descrição de um executivo homem e de uma executiva mulher. Foram descartadas aquelas edições em que as reportagens de capa abordassem mais de um gestor ou gestora simultaneamente, a fim de que pudéssemos analisar com profundidade os textos construídos, tendo como critério de comparação única e exclusivamente o gênero dos indivíduos retratados. Assim, também foram descartadas matérias cujo conteúdo consistisse apenas em entrevistas. A capa como critério para seleção das reportagens foi adotada por se considerar que estas são as que têm mais destaque na respectiva edição, possuem maior apelo comercial e são elucidativas do conteúdo da edição analisada (Rodrigues, 2013).

Desta forma, das 54 edições levantadas e analisadas 11 edições atendiam ao critério de capa e, destas, duas edições ( ${ }^{\circ} 164$ de 2012 e $n^{\circ} 179$ de 2013) atenderam aos critérios de capa e de conteúdo. Dessa forma, as edições $\mathrm{n}^{\circ} 164$ e $\mathrm{n}^{\circ} 179$ constituíram o corpus de análise dessa pesquisa.

O significado representacional foi o foco da análise textual. Dentre as possíveis categorias para explorar este significado, estão a análise do vocabulário e a análise do sistema de transitividade. O traço distintivo mais evidente das formas de representação do mundo é o vocabulário, pois diferentes discursos 'lexicalizam' o mundo de maneiras diferentes. Assim, a análise do vocabulário fornece uma rica evidência, já que as escolhas lexicais para compor um texto são feitas de modo que uma ideia/representação específica de mundo possa ser transmitida. Neste sentido, importa identificar sinônimos, hipônimos, metáforas, adjetivos entre outros aspectos gramaticais que utilizamos na linguagem para expressar determinado ponto de vista, que, por sua vez, revelam a posição sobre um determinado fenômeno.

Já o sistema de transitividade aponta as escolhas léxico-gramaticais que demonstram como a representação de mundo foi construída em determinado texto. De acordo com Salles, Heberle e Macedo (2013), a transitividade é um importante recurso para entender as representações, pois nos permite identificar nos textos os processos, os participantes e as circunstâncias. Desse modo, a transitividade sinaliza nas frases as associações entre o que é realizado (processos) e os papeis atribuídos aos envolvidos (participantes) (Eggins, 2004).

\section{A PRODUÇÃO DO GÊNERO MASCULINO}

A edição da Revista Você S.A. $n^{\circ} 164$ de fevereiro de 2012 traz retratado na capa o empresário Abílio Diniz, com o título da reportagem: Os 17 segredos de Abílio - Abílio Diniz revela os ensinamentos essenciais de liderança que reuniu em 52 anos de trabalho. A reportagem inicia com um breve relato sobre a mudança na carreira do gestor:

[1] Desde que deixou o dia a dia do Grupo Pão de Açúcar, o empresário Abílio Diniz, de $\underline{75}$ anos, decidiu dedicar parte de seu tempo para ensinar o que aprendeu — erros e acertos -

Revista de Gestão Social e Ambiental - RGSA, São Paulo, Edição Especial, p. 06-22, dez. 2017. 
em 52 anos de carreira. Como presidente do Conselho de Administração desde 2003, ele ainda dá expediente no escritório da Avenida Brigadeiro Luís Antônio, no centro de São Paulo, mas tem atendido mais convites de universidades para falar aos estudantes. Há pouco mais de um ano, Abílio também voltou para a sala de aula, na Fundação Getúlio Vargas de São Paulo (FGV-SP), onde se formou, para ensinar conceitos de liderança aos jovens líderes e aspirantes a gestor.

A referência à idade e ao tempo de experiência e o resgate de ações pregressas conferem legitimidade ao personagem por autorização, estratégia linguística de legitimação e racionalização dada por meio da referência à utilidade da ação e ao conhecimento acumulado para conferir validade cognitiva (Fairclough, 2003). O gestor é representado como agente dos processos, a exemplo da passagem o empresário Abílio Diniz, de 75 anos, decidiu dedicar parte de seu tempo para ensinar o que aprendeu.

De acordo com o texto, o gestor decide, ou seja, resolve, toma decisões. A análise do sistema de transitividade revela que Abílio é representado como o agente das ações comunicadas pelos verbos neste e em pelo menos outros oito dos nove trechos que o mencionam. Os substantivos presidente e empresário possuem função identitária no texto: Abílio é descrito como comandante, dirigente de uma empresa, ambos relacionados ao verbo transitivo dirigir, que tem como significado indicar um rumo ou uma direção. Estar à frente da organização como presidente é algo naturalizado ao executivo. $\mathrm{O}$ uso das palavras também e ainda adicionam à função de direção o trabalho de expediente no escritório e a atividade de docência para ensinar conceitos de liderança aos jovens líderes e aspirantes a gestor.

No trecho 2, o gestor é apresentado como uma referência, cujo significado da palavra, segundo o dicionário Michaelis (2016), é "[...]conjunto de qualidades ou características tomado como modelo".

[2] Nos últimos tempos, Abílio vem se tornando uma referência para os jovens profissionais. Pode parecer estranho que aos 75 anos ele figure na lista dos líderes mais admirados do país.

O texto destaca que ele figura na lista dos líderes mais admirados do país. Assim, líder, "[...]pessoa que exerce influência sobre o comportamento, pensamento ou opinião dos outros" (Michaelis, 2016), é o substantivo que nomeia aquilo que o executivo simboliza. Em outro trecho da reportagem, o gestor também é apresentado como exemplo para os jovens. A legitimidade desta informação é construída no trecho 3 , o qual atribui a referência à posição de liderança a uma pesquisa realizada em uma empresa de consultoria:

[3] Abílio apareceu na pesquisa pela primeira vez há dois anos. Na última edição, ficou na oitava posição. O empresário, aponta a pesquisa, representa tudo o que os jovens gostariam de poder fazer: ser dono do seu destino. "Ele faz aquilo que quer da vida", diz Sofia Esteves, presidente do Grupo Dmrh.

O texto apresenta o gestor como agente da ação de simbolizar tudo o que os jovens gostariam de poder fazer. Evidencia-se o uso das aspas no discurso, o que serve especificamente para distanciar a si próprio da voz externa, usando-se da autoridade da voz alheia - neste caso uma mulher presidente de uma empresa de consultoria - para sustentar sua própria posição (Maingueneau, 1997). Nesta frase, as aspas são usadas no sentido de representar a voz dos jovens profissionais, respondentes da referida pesquisa. Desta forma, o texto comunica que o gestor é admirado pelo seu atributo de independência, uma vez que ele faz aquilo que quer da vida e isto é representa tudo o que os jovens gostariam de poder fazer.

O texto prossegue com o trecho 4, no qual a utilização do advérbio de inclusão "também" adiciona aos outros fatores de admiração o fato de, após décadas de trabalho, não dar sinais de querer parar. 
[4] O empresário também é admirado porque, após décadas de trabalho, não dá sinais de que quer parar. "Sou casado com uma mulher de 39 anos, sou pai de seis filhos [o caçula tem 2 anos]. Nesta altura da vida, eu só posso pensar em continuar fazendo planos", diz. Com um comportamento arrojado no mundo dos negócios, Abílio tem a admiração dos jovens também na esfera virtual.

O texto recorre novamente ao uso de aspas, trazendo a voz do próprio gestor para atestar a imagem de ousadia, valentia e audácia comunicados pelo adjetivo arrojado. Isto é feito por meio da afirmação das idades da esposa - 36 anos mais jovem do que ele - e do filho caçula - dois anos - e da quantidade de filhos. O discurso aqui assume contornos claramente patriarcais, destacando a posição assumida pelo homem/marido no âmbito da família (Machado, 2000).

No trecho 5, verifica-se o uso da palavra dedica, verbo pronominal que tem como sinônimo "sacrificar-se por" (Michaelis, 2016):

[5] Ele dedica parte de seu tempo para compartilhar com seus seguidores nas redes sociais e no seu blog o que pensa sobre temas diversos, tais como liderança, equilíbrio entre vida pessoal e profissional e, claro, esportes. O empresário é obcecado por atividades físicas, é triatleta e adora falar sobre futebol.

Assim, para ser admirado também na esfera virtual, o empresário sacrifica parte do seu tempo para compartilhar o que pensa com seus seguidores nas redes sociais e no seu blog. A obsessão por atividades físicas, mencionada na segunda frase, pode ser relacionada a atributos ligados ao gênero masculino como atlético e aventureiro (Gondim et al, 2013).

No trecho 6, a revista aborda o histórico do grupo Pão do Açúcar, organização da qual o gestor é presidente do Conselho de Administração:

[6] O Grupo Pão de Açúcar foi fundado em 1948 por Valentim Diniz, pai de Abílio. No fim da década de 1980, ele assumiu o comando das operações. Com o Plano Collor, a rede de supermercados quase foi à falência. As duas últimas décadas foram de reconstrução. Depois de fusões com Casas Bahia e Ponto Frio, a rede se tornou a maior empregadora privada do país, com 160000 funcionários.

Ao colocar a organização Pão de Açúcar como agente da primeira oração, faz-se uso da estratégia linguística de dissimulação, por meio da qual relações de dominação são ocultadas, negadas ou obscurecidas (Resende; Ramalho, 2006). Esta forma de apresentação permite ofuscar que o gestor seja o herdeiro, aquele que recebe alguma coisa por herança ou direito de sucessão (Michaelis, 2016). Esta estratégia é corroborada ao se analisar o trecho seguinte no qual "ele" (Abílio) é o agente do verbo assumir, sinônimo de alcançar, atingir, chegar até determinado ponto (Michaelis, 2016). Assim, de acordo com o texto, o comando das operações do grupo foi um posto alcançado pelo gestor e não determinado pela circunstância dele ser filho do fundador do grupo.

A matéria prossegue noticiando um episódio desfavorável para a organização. Nota-se neste trecho que o agente da ação é a rede de supermercados, a qual quase foi à falência pela circunstância com o Plano Collor. Tal episódio é imediatamente sucedido pela retomada de um novo período positivo para a organização, trecho no qual o uso das palavras reconstrução e maior evidencia a utilização da eufemização, estratégia linguística por meio da qual se busca uma valoração positiva em relação às ações, relações ou instituições, minimizando-se possíveis instabilidades (Thompson, 1995). Diante destas evidências, verifica-se que a ação do gestor está associada ao assumir o comando da organização, enquanto a quase falência da empresa é associada à circunstância do plano econômico adotado pelo governo da época.

O trecho 7 faz menção ao estilo de liderança do gestor:

[7] Há quem questione e critique o modelo de gestão do executivo. Profissionais que já trabalharam com o empresário afirmam que ele comandava o Pão de Açúcar com mão de 
ferro e que é duro e exigente com seus funcionários - em especial com os executivos (grifos nossos).

O uso da metáfora mão de ferro, para referir-se à forma como profissionais que trabalharam com ele o descrevem, atua como eufemização, valorando positivamente ações ou relações de poder desigual (Thompson, 1995), já que o significante mão de ferro encerra a ideia de um comando enérgico. Já sobre a autoria de possíveis críticas ao estilo de gestão do executivo, há um silenciamento, sendo o agente deste processo ocultado pela expressão há quem.

No trecho 8, a reportagem descreve o gestor por meio do uso do adjetivo pragmático e da afirmação de que ele possui uma visão objetiva de mundo, aspectos tradicionalmente atribuídos ao gênero masculino (Gondim et al, 2013). A voz do executivo é novamente trazida ao texto pela utilização das aspas:

[8] Abílio é um executivo pragmático e com uma visão bem objetiva do mundo. Para ele, fazer o funcionário feliz não é papel somente da empresa. "Só quem consegue equilibrar vida pessoal e profissional e desempenha bem seus papéis na sociedade é feliz”, diz.

$\mathrm{Na}$ análise do texto que trata do gestor Abílio Diniz, pode-se inferir que o gestor foi representado, majoritariamente, como agente das ações, dos nove trechos apresentados anteriormente, em oito sua agência é explícita, sendo estas relacionadas a circunstâncias cuja valoração tem caráter positivo. Ao expor fatos ou circunstâncias de valoração negativa associados às palavras falência e crítica (trechos 6 e 7), os agentes são participantes secundários, tais como o Grupo Pão de Açúcar, a rede de supermercados ou a agência é ocultada, como no uso da expressão há quem critique.

O sistema de transitividade também permitiu evidenciar que o gestor é representado como agente dos verbos decidir, ter, aparecer, representar, figurar, ser, dedicar e assumir. Ainda no texto analisado, destacamos que Abílio Diniz foi mencionado seis vezes por meio da palavra empresário, quatro vezes com a palavra executivo, três vezes líder, uma ocorrência para presidente e sete vezes pelo nome Abílio.

Em síntese, os trechos destacados ilustram que o gestor tem sua representação construída como Abílio, empresário, executivo, líder, pragmático, objetivo, que decide, dedica, assume, aparece, representa e, ainda, que é arrojado, atlético, jovial, independente, tecnológico, durão e aventureiro.

\section{A PRODUÇÃO DO GÊNERO FEMININO}

O outro texto que compõem o corpus, a edição $\mathrm{n}^{\circ} 179$ de abril de 2013 , traz retratada na capa a foto de Maria das Graças Foster cujo título, sobrescrito à imagem, é "Mulheres: elas vão fazer a nova revolução do trabalho?". Este título, diferentemente do título da reportagem de Abílio, na qual ele é referido por seu nome próprio, retrata Marias das Graça por meio do uso do substantivo genérico mulheres. Além disso, o título, ao recorrer a uma frase interrogativa, coloca em questão se as mulheres farão uma revolução, projetando essa possível revolução para um tempo futuro, pela locução verbal vão fazer. Por fim, importa ainda notar nessa interrogação que às mulheres é atribuída a responsabilidade pela tal revolução, marcada pelo pronome elas.

O conteúdo da reportagem se inicia relatando brevemente a situação econômico-financeira da empresa Petrobrás e, paralelamente, ocorre a representação da respectiva gestora.

A reportagem inicia contextualizando a situação da empresa Petrobrás, da qual a gestora era presidente na época em que a revista foi veiculada:

[9] Os últimos meses não têm sido fáceis para Maria das Graças Foster, de 59 anos, presidente da Petrobras, quinta maior companhia de petróleo do mundo. O ano de 2012 foi 
o pior dos últimos seis para a empresa - os custos operacionais aumentaram, o endividamento piorou e a produção de petróleo caiu.

Analisando o vocabulário utilizado percebe-se a conotação negativa que permeia a frase: o adjetivo pior, os verbos piorar e cair e o advérbio de negação não, todas estas palavras possuem uma conotação negativa. No trecho em análise, a identificação da presidente da Petrobrás, Maria das Graças Foster está associada à ideia de mau desempenho, visto que os indicadores econômicofinanceiros da empresa representados pelas palavras custos operacionais, endividamento e produção são acompanhados, respectivamente, das palavras aumentaram, piorou e caiu.

O apagamento de ações, atores ou circunstâncias que contextualizem a situação econômicofinanceira da empresa consiste no modo de operação da ideologia que se dá por meio da reificação, onde se intenta apresentar uma situação transitória como fixa pela omissão de seu caráter sócio histórico. Assim, a leitura do trecho 9 impele o leitor a estabelecer uma única relação possível, sendo esta entre Maria das Graças Foster, Presidente da Petrobras, e o pior dos últimos seis [anos] para a empresa.

A reportagem prossegue comentando as atitudes da gestora:

[10] Graça, como é chamada, precisou acalmar a fúria dos acionistas após informar que o pagamento de dividendos seria reduzido à metade. Negociou com credores e aguentou as pressões políticas.

O texto refere-se à gestora utilizando-se do apelido pelo qual, segundo a reportagem, ela é chamada. $\mathrm{O}$ vocabulário empregado no texto inclui os verbos acalmar - sinônimo de tornar calmo, reduzir um estado de agitação ou de perturbação, serenar, tranquilizar e precisar - ter precisão ou necessidade de; não poder passar sem; não poder prescindir de (Michaelis, 2016). No trecho 10, portanto, a gestora é representada como aquela que acalma, serena, aguenta e negocia, ações que podem ser relacionadas aos atributos de gênero femininos como passiva, submissa e conciliadora (Gondim et al, 2013).

No trecho11, a reportagem enfatiza objetos encontrados no ambiente de trabalho da gestora:

[11] $\mathrm{Na}$ mesa de trabalho da $20^{\mathrm{a}}$ mulher mais poderosa do mundo (segundo a lista da revista americana Forbes), entre as pilhas de relatórios, balanços financeiros e planilhas de resultados também figuram esmalte, remédio para gripe e um DVD do músico inglês Phil Collins.

Analisando o sistema de transitividade do trecho 11 fica evidente que os agentes da ação [figurar] são os objetos esmalte, remédio para gripe e um DVD do músico Phil Collins. O verbo figurar tem como sinônimo representar; formar a figura de; simbolizar (Michaelis, 2016). A ênfase dada a estes objetos, em detrimento de outros [pilhas de relatórios, balanços financeiros e planilhas de resultados] que ficam secundários no contexto da frase, constrói a representação da gestora como vaidosa, frágil e romântica/sentimental.

Em seguida, a reportagem descreve o cotidiano da gestora e resgata sua trajetória de vida:

[12] Graça passa 12 horas por dia em sua sala com vista para a Baía de Guanabara, na sede da Petrobras, no centro do Rio de Janeiro. Se a presidência da Petrobras é um posto inalcançável para a maioria dos profissionais, o que dizer de Graça Foster, que passou a infância na pobreza, no Morro do Adeus, dentro do Complexo do Alemão, no Rio de Janeiro?

A gestora é a agente da ação "passar 12 horas por dia", verbo transitivo cujos sinônimos são "atravessar; empregar; gastar" e que têm como significado "passar de lado a lado; despender; preencher" (Michaelis, 2016). Em relação à circunstância da ação passar, percebe-se que o enfoque na vista da Baía de Guanabara, ponto turístico da cidade do Rio de Janeiro reconhecido nacional e 
internacionalmente pela beleza natural. Assim, ao agrupar palavras dos trechos 11 e 12, sugere-se que a gestora é representada, como aquela que gasta, emprega, preenche 12 horas do seu dia entre esmalte e DVD de música em sua sala com vista para a Baía de Guanabara. Outra questão importante, é a pergunta retórica com a qual o trecho 12 é encerrado - se a presidência da Petrobras é um posto inalcançável para a maioria dos profissionais, o que dizer de Graça Foster, que passou a infância na pobreza, no Morro do Adeus, dentro do Complexo do Alemão, no Rio de Janeiro?

Segundo Fontes (2013) as perguntas retóricas são usadas em momentos da interação em que não se busca uma informação nova, pois já detendo uma resposta a intenção é salientar e chamar a atenção do leitor/ouvinte para uma parte do texto. Nesse sentido, ao tratar a presidência como um posto inalcançável, a improbabilidade de Maria das Graças ter assumido tal cargo é uma resposta evidente no argumento do texto.

Ainda sobre a trajetória profissional da gestora, a reportagem afirma:

[13] Trabalhou na adolescência para comprar material escolar e com sacrifício conseguiu formar-se engenheira química na Universidade Federal Fluminense. Graça entrou na Petrobras em 1978 como estagiária. A partir daí, sua lição de vida inclui uma aula sobre carreira - inspiradora para homens e mulheres.

[14] Foi técnica por dez anos. Tornou-se uma referência em conhecimento dentro da Petrobras e do mercado de óleo e gás. Ficou mais conhecida do público quando assumiu a Secretaria de Petróleo, Gás Natural e Combustíveis Renováveis do Ministério de Minas e Energia no primeiro mandato do governo Lula. Foi a primeira mulher a assumir uma diretoria da Petrobras, em 2007.

No trecho 13, o sistema de transitividade evidencia a ocultação da agência nas ações que remetem a processos ativos como trabalhou e conseguiu formar-se engenheira química. Graça é a agente da ação em entrou na Petrobrás em 1978 como estagiária, posição de menor destaque social. O substantivo utilizado na frase é sacrifício, sinônimo de renúncia. Sendo a engenharia pertencente à área de exatas, a menção ao sacrifício pode remeter ao atributo de gênero feminino "menor capacidade para as ciências exatas" (Gondim et al., 2013).

Ao retratar a trajetória profissional da gestora no trecho 14, a reportagem utiliza-se integralmente da ocultação de sua agência e, alguns momentos da ocultação da circunstância. Assim, a gestora não é um agente reconhecido neste processo. Como afirmam Resende e Ramalho (2006, p.72) "[...]determinados atores podem ter sua agência ofuscada ou enfatizada em representações, podem ser representados por suas atividades ou enunciados ou, ainda, podem ser referidos de modos que presumem julgamentos acerca do que são ou do que fazem". Neste cenário, apesar de a gestora ter uma carreira na organização desde 1978, de ter se tornado uma referência em conhecimento dentro da Petrobras e do mercado de óleo e gás e de possuir qualificação técnica em engenharia química, a circunstância que denota seu reconhecimento ao público é a assunção de uma secretaria no primeiro mandato do governo Lula.

A agência da frase segue oculta na primeira frase do trecho a seguir. Maria das Graças não se tornou presidente:

[15] Foi eleita presidente da empresa em 2012. Hoje, ela lidera 85000 funcionários — 83\% deles homens. No dia em que venceu as eleições de 2010, a presidente Dilma Rousseff declarou que todo pai e toda a mãe do Brasil podiam sonhar que suas filhas ocupassem o cargo mais alto da República. Graça é a versão desse mesmo sonho para o universo das empresas.

Fazendo uma relação entre os trechos 15 e 9, pode-se evidenciar uma estratégia de racionalização: Foi eleita presidente da empresa em 2012 e $O$ ano de 2012 foi o pior dos últimos seis para a empresa. Ou seja, pelas escolhas do vocabulário, do encadeamento de palavras e do agenciamento nas orações, depreende-se a existência de uma relação direta entre a eleição da gestora como presidente da empresa em 2012 e o fato de que este mesmo ano foi o pior dos últimos 
seis para a empresa. Também é possível verificar a presença das palavras sonhar e sonho os quais simbolizam que, para as mulheres, a possibilidade de estar à frente de uma organização ou à frente de um país ainda pertence ao universo do imaginário, da utopia, da fantasia, da ilusão, do intangível, conforme a metáfora sonho utilizada no texto. Graça é representada como agente da ação de ser a versão deste [...] sonho para o universo das empresas.

No trecho 16, Graça é associada à categoria mulheres, operando a ideologia por meio da unificação, com a construção simbólica de uma identidade coletiva, permitindo a sustentação de relações de dominação (Fairclough, 2003).

[16] A trajetória de carreira de Graça coincide com um período particularmente feliz para as mulheres brasileiras. Entre 1980 e 2000, o nível de escolaridade delas ultrapassou o dos homens

O texto recorre à generalização, representando as mulheres (atores sociais) como uma classe indistinta para, desta forma, produzir o consenso de que o nível de escolaridade delas ultrapassou o dos homens. Evidencia-se aqui a hegemonia, o domínio baseado no consenso, na concessão que grupos poderosos fazem a grupos menores, a fim de não desestabilizar o poder (Fairclough, 2001). Desta forma, o texto permite inferir que, se o nível de escolaridade das mulheres ultrapassou o dos homens, isto resulta de um período particularmente feliz para elas, ou seja, resulta de um processo de concessão. Contudo, mesmo que elas estejam mais escolarizadas que os homens, isto não muda o quadro traçado pelo texto de que universo das empresas ainda faz parte de um sonho para as mulheres.

O trecho 17 segue mencionando um período de mudança para as mulheres com relação à formação:

[17] Graça Foster, por exemplo, fez nesse período um mestrado, um MBA e uma especialização. Nos cinco últimos anos, um novo movimento animador começou a se consolidar. Agora, as mulheres estão começando a ingressar nas carreiras tradicionalmente masculinas, principalmente as engenharias.

Estabelecendo uma relação entre a frase as mulheres estão começando a ingressar nas carreiras tradicionalmente masculinas, principalmente as engenharias e a frase com sacrifício conseguiu formar-se engenheira, presente no trecho 13, verifica-se que o discurso subjacente é o da divisão sexual do trabalho o qual, segundo Carloto (2001), utiliza-se do biológico para legitimar o universo feminino na sociedade onde: o mundo da casa, o mundo privado é seu lugar por excelência na sociedade e a entrada na esfera pública, seja por meio do trabalho ou de outro tipo de prática social e política, será marcada por este conjunto de representações do feminino. Desse modo, o discurso implícito aqui presente é o de que: se as mulheres desejam adentrar no universo historicamente construído como pertencente ao masculino, isto não se dará sem que ocorram sacrifícios, mas, ao mesmo tempo, que este é um momento particularmente feliz e animador.

Assim, a análise do texto referente a edição n 179 sobre a gestora Maria das Graças Foster, por meio do sistema de transitividade, evidencia que a gestora é representada pelas ações $i r$, precisar, acalmar, passar, tornar-se, ficar, ser e fazer. Neste texto, as palavras utilizadas para referir-se à Maria das Graças Foster foram: em oito ocorrências "Graça", seu apelido; em cinco ocorrências foi "mulher"; em três, presidente e em apenas uma ocorrência observamos à menção ao seu nome Maria das Graças Foster. Evidenciou-se também que a agência das ações é comumente ocultada, visto que dos nove trechos analisados, em sete sua agência não é revelada.

Em síntese, as evidências apresentadas a partir da análise textual indicam que neste texto a gestora tem sua representação construída como Graça; mulher; presidente da Petrobrás - empresa cujos custos operacionais aumentaram, o endividamento piorou, a produção de petróleo caiu. Graça - seu apelido - é aquela que precisa acalmar; é conciliadora, aguenta e negocia; é vaidosa, frágil e romântica; passa os dias em uma sala com vista para a Baía de Guanabara; com sacrifício adquiriu 
competência técnica; lidera 85000 funcionários - 83\% deles homens; e cuja trajetória profissional coincide com um período particularmente feliz para as mulheres.

\section{A PERSPECTIVA RELACIONAL DA PRODUÇÃO DO GÊNERO: COMPARANDO DISCURSOS}

Pela análise do corpus foi possível observar que o gestor, Abílio Diniz foi representado como agente na maioria das ações, conforme ilustramos por meio dos nove trechos apresentados, dos quais em oito sua agência é explícita. Por outro lado, agência do gestor foi ocultada quando os fatos ou as circunstâncias relatavam uma situação de conflito, notícia negativa ou quando relações diretas precisaram ser dissociadas. Já a gestora, Maria das Graças Foster teve sua agência ocultada na maioria das ações, visto que dos nove trechos apresentados, em sete sua agência não é revelada.

Em relação à identificação dos sujeitos no texto, observou-se que o gestor é identificado pelo seu primeiro nome pelas palavras empresário e executivo, enquanto a gestora é identificada pelo seu apelido ou pela palavra mulher.

Pudemos perceber nos textos que determinadas palavras foram utilizadas para simbolizar aspectos diferentes, como a palavra figurar. No texto que fala sobre o gestor, a palavra é utilizada para afirmar que ele figura na lista dos líderes mais admirados do país. Já no texto sobre a gestora, quem figura são esmalte, batom e DVD do músico Phil Collins.

Ao descrever o ambiente de trabalho do gestor, a reportagem deteve seu enfoque sobre o endereço de seu escritório, no centro de São Paulo. Ao descrever o ambiente de trabalho da gestora, o enfoque se deu sobre os objetos presentes no ambiente [entre as pilhas de relatórios, balanços financeiros e planilhas de resultados também figuram esmalte, remédio para gripe e um DVD do músico inglês Phil Collins], assim como para a vista de sua sala. De acordo com o texto Abílio Diniz dá expediente em seu escritório, enquanto Maria das Graças Foster passa metade do seu dia em sua sala com vista para a Baía da Guanabara.

Ainda, percebe-se que o gestor foi representado com atributos como independência, afirmação sexual por quantidade, objetividade, firmeza, rigidez, atlético, aventureiro e que conduz com mão de ferro a organização. Já a gestora teve seu perfil descrito a partir dos atributos de passividade, conciliação, fragilidade e romantismo.

Estes achados evidenciam a representação estereotipada dos gestores sob a perspectiva de gênero, sendo possível identificar nos trechos analisados atributos considerados como predominantemente femininos na representação da gestora e atributos predominantemente masculinos na representação do gestor. Como destaca Miranda (2008), os estereótipos consistem em crenças partilhadas sobre traços de personalidade e comportamento os quais contribuem para a naturalização das funções sociais atribuídas a homens e mulheres.

\section{CONSIDERAÇÕES FINAIS}

Como foi possível verificar, o corpus apresenta um discurso pautado na naturalização como justificativa para as posições sociais desempenhadas pelos gestores retratados nas reportagens analisadas. Nesse sentido, é natural que a gestora enquanto mulher acalme a fúria dos acionistas, uma vez que a feminilidade foi uma dimensão historicamente construída como associada ao cuidado e à preocupação com a coletividade. Assim como também é naturalizado ao gestor que ele possua uma visão bem objetiva de mundo e que conduza os negócios com mão de ferro, uma vez que a masculinidade foi historicamente construída como uma dimensão ligada à assertividade e à individualidade (Gondim et al., 2013).

Os discursos analisados parecem remeter à literatura organizacional dos anos 50 e 60, quando a presença das mulheres em posições gerenciais era considerada uma anomalia, sendo consideradas normais apenas sua presença em posições subalternas (Calás; Smircih, 2010). 
As representações estereotipadas dos gestores trazidas pelo discurso analisado detêm a força de se estabelecer como limitadores sobre as escolhas e possibilidades de ação social dos indivíduos, uma vez que imprimem uma aparência de normatividade em relação à gestão sob a perspectiva do gênero. De acordo com Wood Jr. e Paula (2002), a literatura pop-management não só contribui para a disseminação de ideias e práticas gerenciais como também influencia a construção das agendas dentro das organizações, o que reforça o potencial limitador e normativo destes discursos. Em última análise, a partir do conceito de tecnologia de gênero proposto por Lauretis (1994), entendemos que a revista Voce Sa constrói gênero quando retrata Maria das Graças e a Abílio por meio de atributos femininos e masculinos que os definem e diferenciam. São as marcas sociais, definidas pelos atributos construídos no discurso da revista, que posicionam estas pessoas como gestora mulher e gestor homem. Considerando-se ainda que os atributos de gênero reportados como próprios ao gestor ou à gestora foram comunicados por meio de estratégias de construção simbólicas como a universalização e a naturalização, reconhecidos modos de operação da ideologia, sugerimos que ocorre neste discurso uma repetição da visão de mundo hegemônica, na qual o masculino é construído positivamente em detrimento do feminino.

Nesse sentido, a repetição da visão de mundo hegemônica nos discursos midiáticos confere à mídia a potencialidade de constituir-se enquanto instituição capaz de garantir a ignorância bem como sustentar a criação de uma realidade à luz do discurso hegemônico. Entendemos que o corpus analisado ilustra bem a afirmação de Resende e Ramalho (2006, p.113), ao demonstrar que

[...]a naturalização tanto da representação que privilegia determinados atores e vozes quanto das metáforas que inculcam sentidos negativos possibilita a ação da ideologia por meio da violência simbólica que carrega consigo o poder de impor - e mesmo de inculcar instrumentos de conhecimento e de expressão arbitrários, embora ignorados como tais - da realidade social.

Nosso trabalho pretende contribuir, sob este aspecto, evidenciando que, dado o alcance da Revista Você S.A. e sua legitimidade perante um público crescente, pode-se entender a revista como uma tecnologia de gênero, "[...]com poder de controlar o campo do significado social e assim produzir, promover e implantar representações de gênero (Lauretis, 1994, p.228)". Para completar a análise da revista como tecnologia de gênero, seria interessante desenvolver outros estudos para avaliar não apenas como o aparelho midiático representa o gênero, ou seja, a perspectiva a partir da qual a imagem é construída, mas também como os homens e mulheres recebem, reconstroem e reproduzem estas imagens na/como subjetividade (Lauretis, 1994).

Percebe-se, portanto, que há muito a avançar no que diz respeito à compreensão das representações de homens e mulheres no contexto do trabalho gerencial. Outro aspecto relevante seria romper com a polaridade conceitual entre os gêneros e com a unidade interna de cada um na problematização da atuação em postos de gestão. Consideramos que esta foi uma limitação do nosso estudo, inerente às características do corpus analisado, na medida em que a perspectiva que adotamos, ao comparar atributos femininos e masculinos presentes no discurso das reportagens analisadas, ainda pode ser considerada dicotômica, evidenciando a relação binária "homens" e "mulheres" a qual se conforma em uma matriz heterossexual de conceituação do gênero (Butler, 2015). Como sugere Butler $(2015$, p.13) “[...]a complexidade do conceito de gênero exige um conjunto interdisciplinar e pós-disciplinar de discursos, com vistas a resistir à domesticação acadêmica dos estudos sobre gênero ou dos estudos sobre as mulheres[...]", radicalizando assim a crítica feminista.

\section{REFERÊNCIAS}

Acker, J.(1990) Hierarchies, jobs, bodies: a theory of gendered organizations. Gender and Society, 4(2), 139-158, jun. 
Butler, J.(2015) Problemas de gênero: feminismo e subversão da identidade. (8.ed.) Rio de Janeiro: Civilização Brasileira.

Calás, M., Smircich, L.(2010) Do ponto de vista da mulher: abordagens feministas em estudos organizacionais. In: Caldas, M; Fachin, R; Fischer, T (Org.). Handbook de estudos organizacionais. São Paulo: Atlas, 273-360.

Cappelle, M., Brito, M., Melo, M., Vasconcelos, K. A produção científica sobre gênero nas organizações: uma meta-análise. Revista Eletrônica de Administração, [S.1.], 13(3), p. 502-528, maio 2013.

Carvalho, J. Carvalho, F. Bezerra, C.(2010) O monge, o executivo e o estudante ludibriado: uma análise empírica sobre leitura eficaz entre alunos de administração. Cadernos Ebape, 8(3), 535-549, set.

Diniz, A.(2016) Feminilidades e masculinidades no trabalho. In.: Gênero e trabalho: perspectivas, possibilidades e desafios no campo dos estudos organizacionais. Salvador: Edufba, p.131-158.

Eccel, C. S.(2010) Estudos de gênero nas organizações: implicações teórico-metodológicas. In: Encontro Nacional da Associação de Pós-Graduação em Administração, 34. Rio de Janeiro. Anais... Rio de Janeiro: Anpad, 1-15 p.

Eggins, S.(2004) An introduction to systemic functional analysis. (2 ed.) Continum: Editor. Fairclough, N.(2001) Discurso e mudança social. Tradução de Izabel Magalhães. (1. ed.) Brasília: Universidade de Brasília, 320 p.

Fairclough, N. (2003) Analysing discourse: textual analysis for social research. London: Routledge.

Gondim, S. Sobrinho, J. Santana, V. Santos, V. Saveia, J.(2013) Gênero, autoconceito e trabalho na perspectiva de brasileiros e angolanos. Cadernos de Psicologia Social do Trabalho, Salvador, 16(2), 153-165, abr.

Kergoat, D.(2009) Divisão sexual do trabalho e relações sociais de sexo. In.: Hirata, H. Laborie, F. Doaré, H. Senotier, D. Dicionário crítico do feminismo. São Paulo: Editora Unesp.

Lauretis, T.(1994) A tecnologia do gênero. In: Hollanda, H. B. de. Tendências e impasses. $O$ feminismo como crítica da cultura. Rio de Janeiro: Rocco.

Louro, G.(2014) Gênero, sexualidade e educação: uma perspectiva pós-estruturalista. (16.ed.) Petrópolis, RJ: Vozes, 18-60.

Machado, L.(2000) Perspectivas em confronto: relações de gênero ou patriarcado contemporâneo? In: Sociedade Brasileira de Sociologia (Ed.) Simpósio Relações de Gênero ou Patriarcado Contemporâneo. Reunião Brasileira para o Progresso da Ciência, 52. Brasília: SBP.

Medeiros, C. Borges, J. Miranda. J.(2010) Estereótipos de gênero e carreira executiva na literatura gerencialista. Revista Gestão.Org, 8(1), 81-97.

Melo, M. Capelle, M. Mageste, G. Brito, M.(2004) Representações femininas na mídia de negócios brasileira. $O \& S-11(31), 103-118$, set./dez. 
Miguel, L. Biroli, F.(2014) Feminismo e política. São Paulo: Boitempo Editorial.

Miguel, L.(2001) Política de interesses, política do desvelo: representação e "singularidade feminina". Revista Estudos Feministas, Florianópolis, 9(1), 253-266, jun.

Pereira, P.(2009) Violência e tecnologias de gênero: tempo e espaço nos jornais. Rev. Estud. Fem., Florianópolis, 17(2), 485-505, Aug.

Resende, V., Ramalho, V.(2006) Análise de discurso crítica. São Paulo: Contexto.

Rodrigues, M. (2013) O novo ministério da verdade: o discurso de veja sobre o campo do ensino superior e a consolidação da empresa no Brasil. $410 \mathrm{f}$. Tese (Doutorado em Administração) Universidade Federal de Santa Catarina, Florianópolis.

Salles, H. Heberle, V. Macedo, L.(2013) O futuro que queremos? uma análise da representação da mulher no relatório final da RIO+20. In: Encontro Nacional da Associação de Pós-Graduação em Administração, 37. Anais... Rio de Janeiro: Anpad, 1-14 p.

Scott, J.(1995) Gênero: uma categoria útil para a análise histórica. Educação \& Realidade, 20(2), 71-99.

Van Dijk, T.(2010) Discurso e poder. (2. ed.) São Paulo: Contexto.

Vilas Boas, L. Neto, A. Cramer, L.(2003) Relações de gênero nas organizações: um estudo no setor de vendas de veículos. Revista de Administração, São Paulo, 38(3), 219-229, jul.

Voce Sa. (2016) Mídia kit. Recuperado em: 03 abril 2017, de:

file:///C:/Users/Usuario/Downloads/VCSA-Midia-kit-2017.pdf.

Wodak, R.(2004) Do que trata a ACD - um resumo de sua história, conceitos importantes e seus desenvolvimentos. Revista Linguagem em (Dis)curso, 4(especial), 223-243.

Wood Jr, T., Paula, A.(2002) Pop-management: contos de paixão, lucro e poder. $O \& S$. Salvador, 9(24). maio-agosto.

Data da submissão: 27/04/2017

Data de aceite: 19/06/2017 